\title{
C-Met Inhibitor MK8033
}

National Cancer Institute

\section{Source}

National Cancer Institute. c-Met Inhibitor MK8033. NCI Thesaurus. Code C116866.

An orally bioavailable inhibitor of c-Met, with potential antineoplastic activity. Upon administration, c-Met inhibitor MK8033 binds to and inhibits the autophosphorylation of the c-Met protein, which disrupts c-Met signal transduction pathways and may induce cell death in tumor cells overexpressing or expressing constitutively activated c-Met protein. In addition, MK8033 inhibits Ron (receptor orig inated from nantes, MST 1R). c-Met protein, which is encoded by the proto-oncogene MET, is a receptor tyrosine kinase also known as hepatocyte growth factor receptor (HGFR); this protein is overexpressed or mutated in many tumor cell types and plays key roles in tumor cell proliferation, survival, invasion, and metastasis, and tumor angiogenesis. Ron, a member of the Met family of cell surface receptor tyrosine kinases, is also overexpressed on certain tumor cell types. 